\title{
Clinical craft: a lesson from Liverpool
}

D M Gore University of Liverpool

\begin{abstract}
Inspiration in medical humanities can be intense and personal, and does not necessarily require the portrayal of health issues.

(F Med Ethics: Medical Humanities 2001;27:74-75)
\end{abstract}

The enduring appeal of the humanities is that they allow one to experience emotion vicariously. The skill of a great artist is the compelling portrayal of emotion, and this skill endures with his or her work. Occasionally we identify with a character in drama or literature to such an extent that the connection fixes itself in our mind and indeed becomes a reference for our consciousness. These epiphanies are precious; the process of connection is so intensely personal that it defies prescription. We might identify with characters of both popular and highbrow works. Furthermore, emotion colours moral concepts of right and wrong, and as we explore the humanities, we become both more emotionally and more morally articulate. This assertion is utterly beyond scientific critique; as a cultural expectation it has been with us for centuries and needs no statistical validation. Indeed to try to quantify this experience is to fail to understand it.

Medical humanities seek to harness personal development through the arts for the purpose of making better doctors. While a medical humanities syllabus might focus on portrayals of ill health in art, we can find connections relevant for our own clinical practice in the broader experience of the humanities. Recently I had an epiphany from the drama of an unemployed plasterer.

I am a specialist registrar in general surgery and I came to Liverpool in 1999 to undertake a basic science research project. In my free time I set about exploring the city and its lore. Liverpool has taken many knocks over the years and is as poor a city as one will find in England. Notoriously bleak in the 1980 s, the struggle of daily life there was famously portrayed in Alan Bleasdale's acclaimed 1982 BBC television drama series, Boys from the Blackstuff . I was determined to reacquaint myself with it and was happy to find it available as a BBC video. The era of this gritty social realism might or might not have passed, but the characters retain their power anyway.

Snowy Malone is a plasterer, and as a skilled tradesman he takes pride in his work. Unable to find regular employment, he is reduced to "doing the double"-claiming unemployment benefit and working for cash in hand-to make ends meet. Moonlighting for an unscrupulous and exploitative contractor chafes against his left wing principles; indeed those principles run in the family, his father being a local hero for his dock labour agitation and community representation. Nevertheless in the first episode of the series Snowy is plastering in a renovated building, ropes hanging out of the window to afford a quick exit lest dole snoopers appear. He declares to his mate Chrissie why he likes plastering:

'I love doin' this, y'know . . . . I'd plaster for nothing if my principles would let me-know what I mean? . . .. Y'know, doing something y' good at. There's nothin' like it. Standin' there in the morning facin' four empty walls - an' then home at night with the plaster all dry and smooth-an' the bit you've just done all wet and shinin'. That's why I don't mind workin' on me own, if the truth be told, because if there's one thing I can't stand, it's working with someone who hasn't got no pride."

The social security fraud squad raids the site; Snowy grabs his rope and climbs out of the window. The rope breaks and Snowy lies dead on the ground outside. The irony of the plot is that the building is being renovated as a dole office.

I have never seen, heard or read a more poignant affirmation of the value of doing a skilled job well for its own sake. That was my epiphany. Snowy is a time-served plasterer; I am a qualified surgeon. Like Snowy, I get satisfaction simply from doing my job well. My satisfaction is not a function of patients' gratitude, although it is a privilege to have that as an occasional perk. Nor is it a glow of altruism; I can't claim that I could match Snowy's commitment to doing the job for free.

Any clinician is a practitioner of a craft; assessing a patient by history and examination, addressing diagnostic possibilities, counselling patient and relatives. Many clinicians have technical craft skills on top, surgeons in particular, but no clinician practises well with technical skill alone. Our basic clinical and ward-management skills tend not to be celebrated as they might; they're not particularly exciting, novel or high-tech. But neither is plastering, yet Snowy Malone spoke to me in that episode.

Surely now is a good time to revisit the concept of clinical craft. Certainly as doctors we are professional people in the sense that we have a governing body which prescribes duties and responsibilities, but our prestige has been tarnished by accusation and allegation. We do need a dose of humility to atone for the excesses of our medical arrogance. Despite our caring rhetoric, we doctors still imbibe arrogance from our medical culture. One only has to look at the squalor of the average doctors' mess to realise that even junior doctors feel themselves too important to clean up after themselves. But we 
also need a certain amount of pride to keep up our morale. By celebrating our craft we can identify with skilled workers anywhere. I might not mix much with plasterers but I can respect them for their skill, and what is more I can share their satisfaction in doing a good job well.

Perhaps it is precocious for a registrar to be uttering such self-indulgent profundities; perhaps I was reacting to being taken out of my usual clinical environment and put in a research laboratory. But so what? I made a connection with Snowy Malone; and as a result I might have learned a little humility, a little respect, and I am more determined than ever to be a good clinician.

D M Gore, FRCS, is a Research Fellow in the Department of Surgery, University of Liverpool.

\section{News and notes}

Colleagues from the Universities of Leeds, Sheffield and Leicester met in September 2001 at Leeds Medical School to discuss teaching humanities subjects within the medical curriculum. Several different disciplines and organisations were represented, all of which expressed an interest in teaching and broadening current medical training. We had a wide ranging discussion about the value of the humanities for medicine and touched on the difficulties entailed in the evaluation of courses that have more to do with developing "attitudes" than with "knowledge" and "skills".

Dr Paul Lazarus led a debate on the use of student learning journals and their use as a reflective tool in education Debate concerned the extent to which such journals should be private property or public and used for assessment purposes. There were also two poster presentations of Special Study Modules in Literature and Creative Writing from Sheffield and Written Communication from Leeds.

Arising from the meeting, the group decided on the following aims and aspirations, to be promoted by means of regular meetings and by group or interpersonal communication:

- to promote the role of medical humanities within medical, nursing schools, health care institutions and to society in general, and to consider formulating a consensus statement on the values of medical humanities in education and in improving patient outcomes, to be offered as a guide for individual centres when planning their curricula or other initiatives

- to explore methods of evaluating the efficacy of medical humanities

- to function as a regional network, relating directly to the forthcoming nationally based Association for Medical Humanities.

Apologies for absence were received from Newcastle, Durham, Birmingham, and Nottingham. We plan to meet again in March 2002, after the AMH has held its inaugural meeting on 9th February.

Further information: Dr Emma Storr, Communication Skills Unit, MEU Level 7 Worsley Building, University of Leeds, LS2 7NL. e.storr@leeds.ac.uk

Dr Paul Lazarus, Department of Primary Care, University of Leicester, Leicester General Hospital, LE1 4PW. pal6@lei.ac.uk 